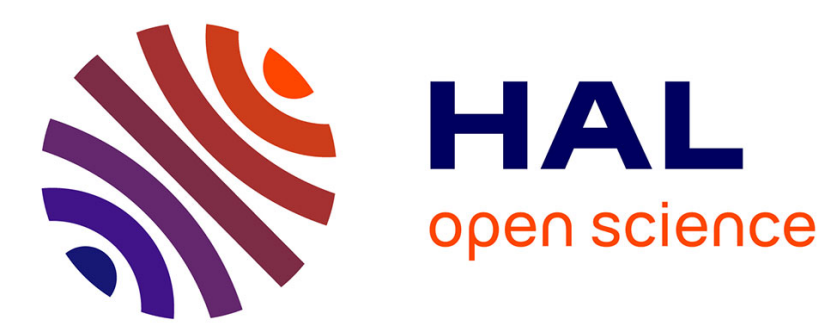

\title{
A New Design for the Gravelectric Generator
}

\author{
Fran de Aquino
}

\section{- To cite this version:}

Fran de Aquino. A New Design for the Gravelectric Generator. 2021. hal-03231614v2

\section{HAL Id: hal-03231614 \\ https://hal.science/hal-03231614v2}

Preprint submitted on 27 May 2021 (v2), last revised 31 May 2022 (v4)

HAL is a multi-disciplinary open access archive for the deposit and dissemination of scientific research documents, whether they are published or not. The documents may come from teaching and research institutions in France or abroad, or from public or private research centers.
L'archive ouverte pluridisciplinaire HAL, est destinée au dépôt et à la diffusion de documents scientifiques de niveau recherche, publiés ou non, émanant des établissements d'enseignement et de recherche français ou étrangers, des laboratoires publics ou privés. 


\title{
A New Design for the Gravelectric Generator
}

\author{
Fran De Aquino \\ Professor Emeritus of Physics, Maranhao State University, UEMA. \\ Titular Researcher (R) of National Institute for Space Research, INPE \\ Copyright $@ 2021$ by Fran De Aquino. All Rights Reserved. \\ www.frandeaquino.org \\ deaquino@elointernet.com.br
}

In a previous paper, we have proposed a system called Gravelectric Generator to convert Gravitational Energy directly into Electrical Energy [1]. Here we show a new design for the Gravelectric Generator. This system can have individual outputs powers of several tens of kW. It is easy to be built, and can easily be transported.

Key words: Gravitational Electromotive Force, Gravitational Energy, Electrical Energy, Generation of Electrical Energy.

\section{INTRODUCTION}

The electrical current arises in a conductor when an outside force acts upon the free electrons of the conductor. This force is called, in a generic way, of electromotive force (EMF). Usually, it has electrical nature. In a previous paper we have shown that this force can have gravitational nature (Gravitational Electromotive Force), and we have proposed a system to produce Gravitational Electromotive Force, called Gravelectric Generator, which converts Gravitational Energy directly into Electrical Energy [1].

A new design for the Gravelectric Generator is shown in this paper. This system can have individual outputs powers of several tens of $\mathrm{kW}$. It is easy to be built, and can easily be transported.

\section{THEORY}

Consider a coil with iron core. Through the coil passes a electrical current $i$, with frequency $f_{H}$. Thus, there is a magnetic field with frequency $f_{H}$ through the iron core. If the system is subject to a gravity acceleration $g$, then the gravitational forces acting on electrons $\left(F_{e}\right)$, protons $\left(F_{p}\right)$ and neutrons $\left(F_{p}\right)$ of the Iron core, are respectively expressed by the following relations [2]

$$
\begin{aligned}
& F_{e}=m_{g e} a_{e}=\chi_{B e} m_{e 0} g \\
& F_{p}=m_{g p} a_{p}=\chi_{B p} m_{p 0} g \\
& F_{n}=m_{g n} a_{n}=\chi_{B n} m_{n 0} g
\end{aligned}
$$

$m_{g e}, m_{g p}$ and $m_{g n}$ are respectively the gravitational masses of the electrons, protons and neutrons; $m_{e 0}, m_{e 0}$ and $m_{e 0}$ are respectively the inertial masses at rest of the electrons, protons and neutrons.

The expressions of the correlation factors $\chi_{B e}, \chi_{B p}$ and $\chi_{B n}$ are deduced in the paper [ $\underline{3}$ ] and Appendix of []ㅡ, and are given by

$$
\begin{aligned}
\chi_{B e} & =\left\{1-2\left[\sqrt{1+\frac{45.56 \pi^{2} k_{x e}^{22} r_{e}^{4} B_{r m s}^{4}}{\mu_{0}^{2} m_{e}^{2} c^{2} f^{2}}}-1\right]\right\}= \\
& =\left\{1-2\left[\sqrt{1+1.5 \times 10^{23} \frac{B_{r m s}^{4}}{f^{2}}-1}\right]\right\} \\
\chi_{B p} & =\left\{1-2\left[\sqrt{1+\frac{45.56 \pi^{2} r_{p}^{4} B_{r m s}^{4}}{\mu_{0}^{2} m_{p}^{2} c^{2} f^{2}}}-1\right]\right\} \\
\chi_{B n} & =\left\{1-2\left[\sqrt{1+\frac{45.56 \pi^{2} r_{n}^{4} B_{r m s}^{4}}{\mu_{0}^{2} m_{n}^{2} c^{2} f^{2}}}-1\right]\right\}
\end{aligned}
$$

where $k_{x e} \cong 1.9 \quad$ (See Appendix [1] ) ; $r_{e} \cong 1.4 \times 10^{-10} \mathrm{~m} ; \quad r_{p}=1.2 \times 10^{-15} \mathrm{~m}, r_{n} \cong r_{p} . \quad$ [1] . Note that $\chi_{B n}$ and $\chi_{B p}$ are negligible in respect to $\chi_{\mathrm{Be}} \cdot$

It is known that, in some materials, called conductors, the free electrons are so loosely held by the atom and so close to the neighboring atoms that they tend to drift randomly from one atom to its neighboring atoms. This means that the electrons move in all directions by the same amount. However, if some outside force acts upon the free electrons their movement becomes not random, and they move from atom to atom at the same direction of the applied force. This flow of electrons (their electric charge) through the conductor produces the electrical current, which is defined as a flow of electric charge through a medium [4]. This charge is typically carried by moving electrons in a conductor, but it can also be carried by ions in an electrolyte, or by both ions and electrons in a plasma []․

Thus, the electrical current arises in a conductor when an outside force acts upon its free electrons. This force is called, in a generic 
way, of electromotive force (EMF). Usually, it is of electrical nature $\left(F_{e}=e E\right)$. However, if the nature of the electromotive force is gravitational $\left(F_{e}=m_{g e} g\right)$ then, as the corresponding force of electrical nature is $F_{e}=e E$, we can write that

$$
m_{g e} g=e E
$$

According to Eq. (1) we can rewrite Eq. (7) as follows

$$
\chi_{B e} m_{e 0} g=e E
$$

Now consider a wire with length $l$; cross-section area $S$ and electrical conductivity $\sigma$. When a voltage $V$ is applied on its ends, the electrical current through the wire is $i$. Electrodynamics tell us that the electric field, $E$, through the wire is uniform, and correlated with $V$ and $l$ by means of the following expression [6]

$$
V=\int \vec{E} d \vec{l}=E l
$$

Since the current $i$ and the area $S$ are constants, then the current density $\vec{J}$ is also constant. Therefore, it follows that

$$
i=\int \vec{J} . d \vec{S}=\sigma E S=\sigma(V / l) S
$$

By substitution of $E$, given by Eq.(9), into Eq.(8) yields

$$
V=\chi_{B e}\left(m_{e 0} / e\right) g l
$$

This is the voltage $V$ between the ends of a metallic cylinder, when it has conductivity $\sigma$ and cross-section area $S$, and it is subjected to a uniform magnetic field $B_{H}$ with frequency $f_{H}$, and a gravity $g$ (as shown in Fig.(1)) (The expression of $\chi_{B e}$ is given by Eq. (4)).

Substitution of Eq. (11) into Eq. (10), gives

$$
i=\chi_{B e}\left(m_{e 0} / e\right) \sigma g S
$$

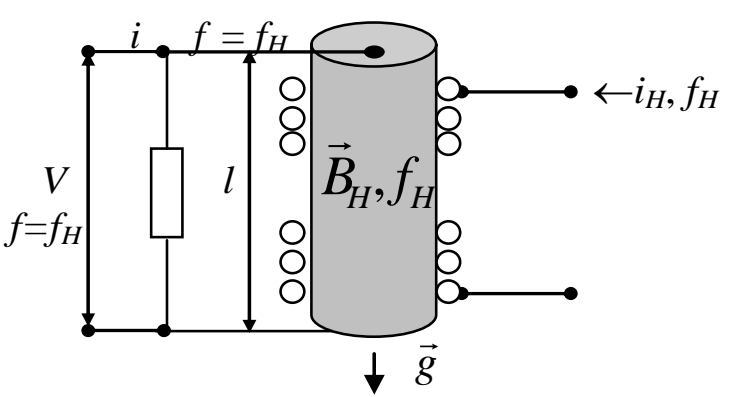

Fig. 1 - The voltage $V$ between the ends of a metallic cylinder when it is subjected to a uniform magnetic field $B_{H}$ with frequency $f_{H}$, and gravity $g$ (as shown above).
Substitution of Eq. (4) into Eq. (11) and Eq.(12) yields respectively

$V=\left\{1-2\left[\sqrt{1+1.5 \times 10^{23} \frac{B_{r m s}^{4}}{f^{2}}}-1\right]\right)\left(\frac{m_{e 0}}{e}\right) g l$

and

$$
i=\left\{1-2\left[\sqrt{1+1.5 \times 10^{23} \frac{B_{r m s}^{4}}{f^{2}}}-1\right]\right\}\left(\frac{m_{e 0}}{e}\right) \sigma g S
$$

If $B_{r m s}=B_{H(r m s)}=1.2 T$ and $f=f_{H}=60 H z$, then Eq. (13) and (14) give, respectively

$$
\begin{aligned}
& V \cong 1.03 l \\
& i=1.03 \circ S
\end{aligned}
$$

For iron wire \# 12 BWG, $\left(\phi=2.77 \mathrm{~mm} ; \sigma=1.04 \times 10^{7} \mathrm{~S} / \mathrm{m}\right)$, with length $l$

(See Fig. 2) given by

$l=2 \times 76[(2 \times 0.55)+2 \times 0.15]+2 \times(0.55+0.15)=$ $=2128+1.4=214.2 \mathrm{~m}$

the Eq. (15) and Eq. (16) give, respectively

$$
V \cong 220 \text { olts }
$$

and

$i_{\max (\text { theoretica } l)}=8.4 \times 10^{6} \phi^{2}=64.4 \mathrm{~A}$

However, the maximum current supported by an iron wire \# 12 BWG, $\phi=2.77 \mathrm{~mm}$ is approximately13 $A$, i.e., $\quad i_{\max (\text { real })}=13 A$. Consequently, in this case, the maximum output power of the Gravelectric Generator is

$$
P_{\text {max (real) }}=V i_{\text {max (real })} \cong 2.8 \mathrm{~kW} \cong 3.7 \mathrm{HP}
$$

Note that, if the diameter of the iron wire increases up to $\phi=13 \mathrm{~mm}$ the value of $i_{\max (\text { theoretical) }}$ increases up to $1419.6 A$ (See Eq. (18)) and the power would increase up to $312 \mathrm{~kW}$. However, the maximum current supported by an iron wire with diameter $13 \mathrm{~mm}$ is approximately 360A. Thus,

$P_{\max (\text { real })}=220 \mathrm{~V} \times 360 \mathrm{~A}=79.2 \mathrm{~kW} \cong 106 H P \quad(20)$

This power is sufficient to feed the electric motor of most electric cars.

\footnotetext{
In the US typical household power consumption is about $1.3 \mathrm{~kW}$ per hour. In 2013, the average annual electricity consumption for a U.S. residential utility customer was $10,908 \mathrm{kWh}$ [7]. Then, in order to provide the amount energy of $1.3 \mathrm{kWh}$ it is necessary that the electric generator has power $P=1300 \mathrm{kWh} / 720 \mathrm{~h}=1.8 \mathrm{~kW}$. Equation (19) shows that the Gravelectric Generator is able to produce a much more than this value.
} 


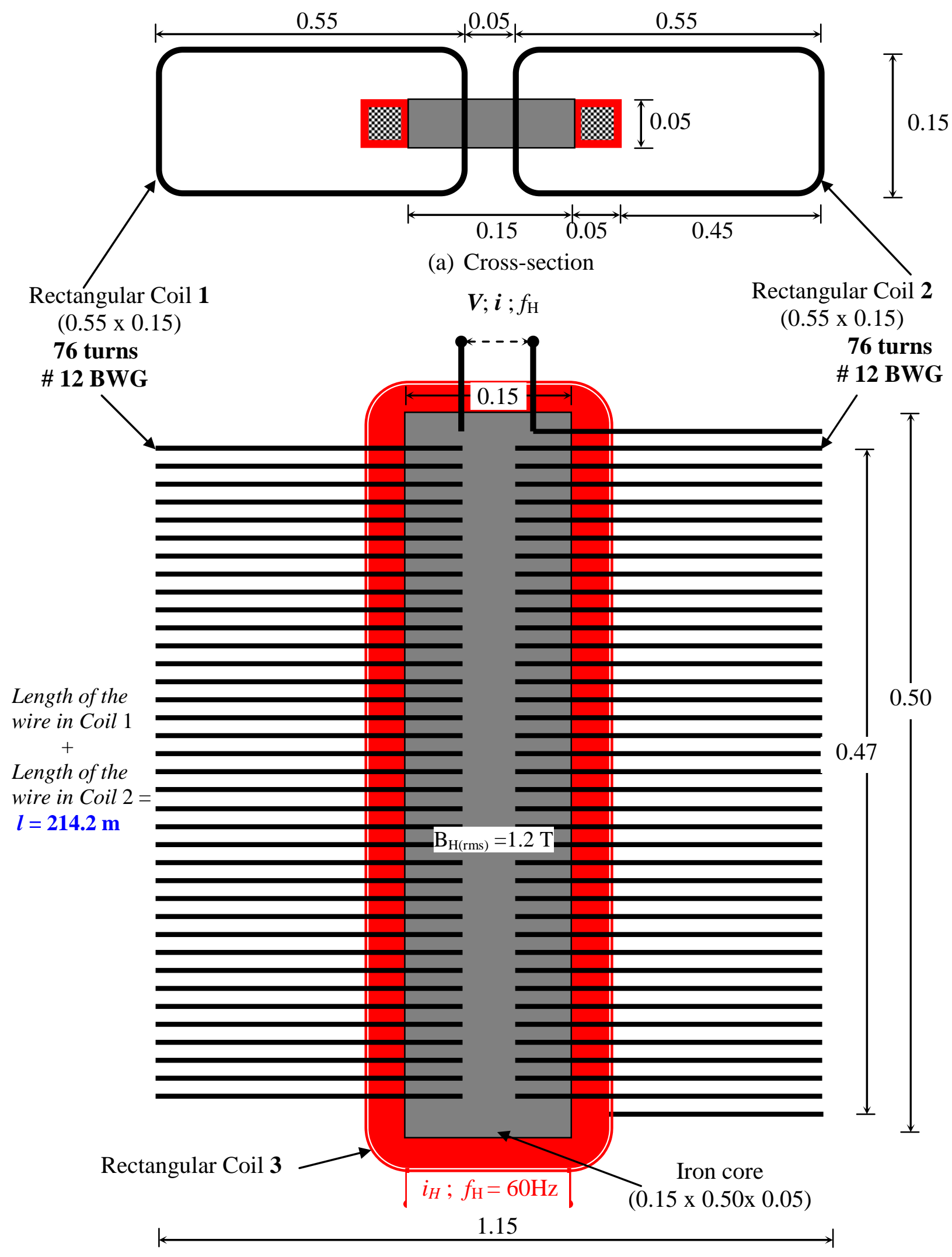

(b) Top view

Fig. 2 - Schematic diagram of the Gravelectric Generator as energy source up to $2.8 k W \cong 3.7 H P$ 


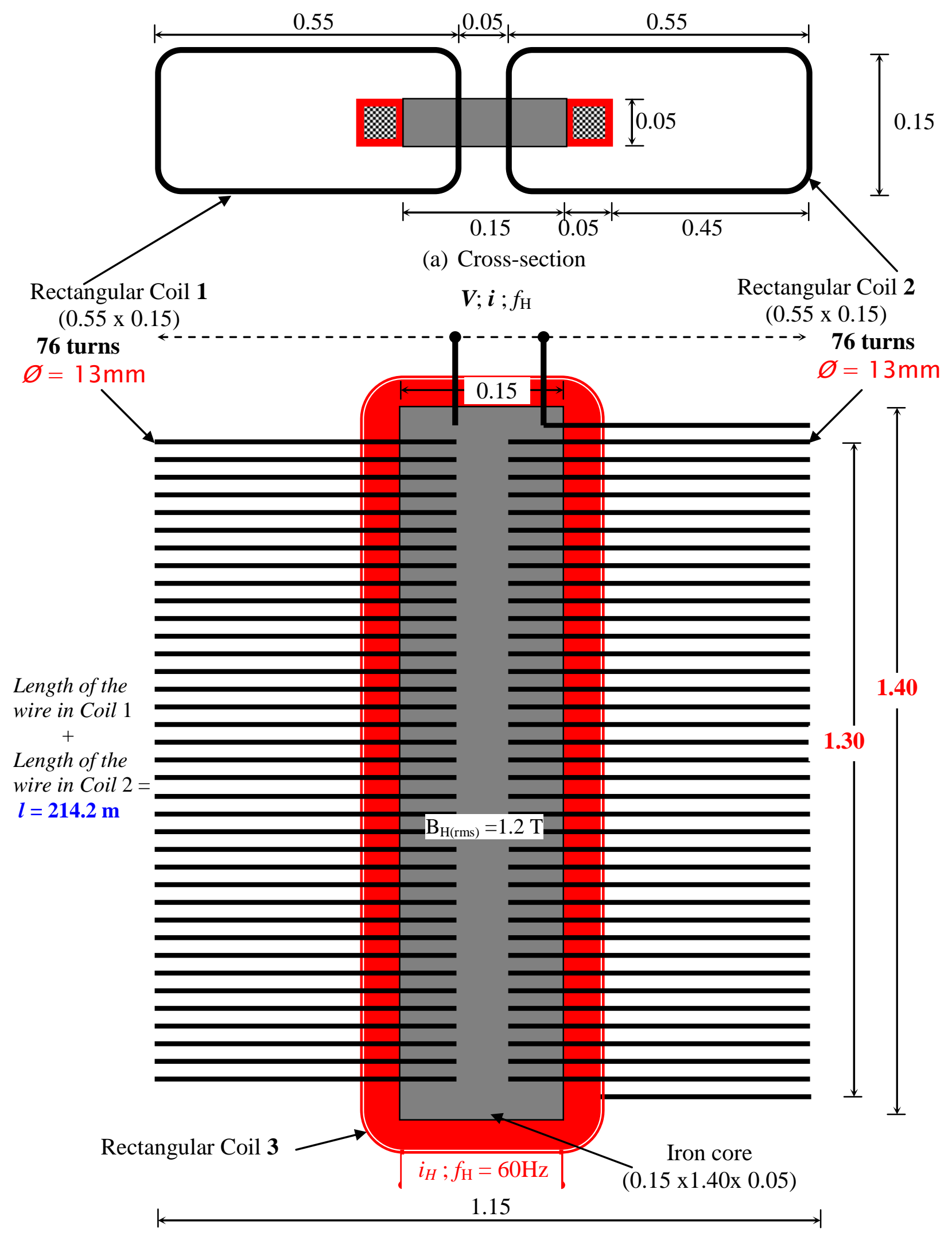

(b) Top view

Fig. 3 - Schematic diagram of the Gravelectric Generator as energy source up to $79.2 \mathrm{~kW} \cong 106 H P$ 


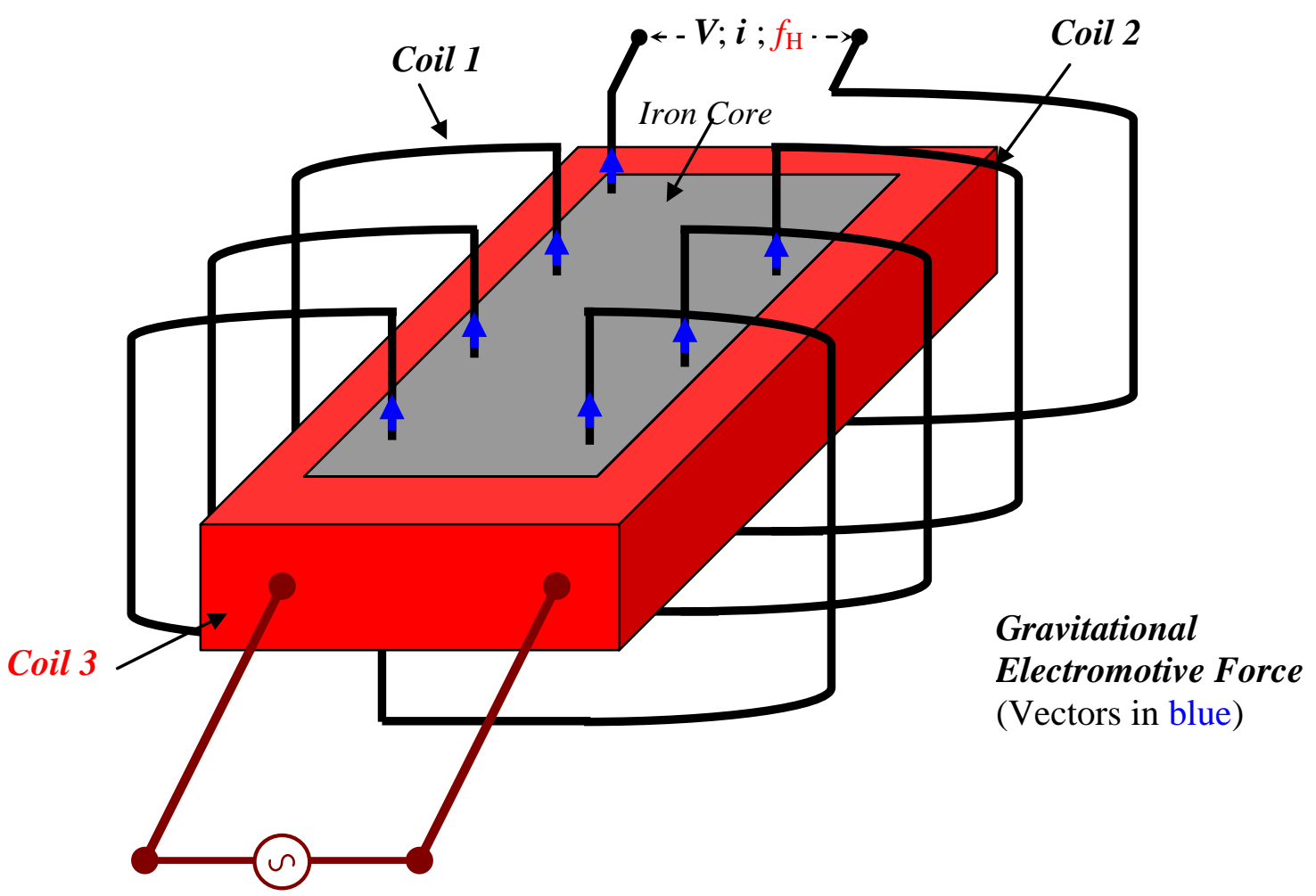

$i_{H} ; f_{\mathrm{H}}=60 \mathrm{~Hz}$

Fig. 4 - Perspective (Schematic Diagram) 


\section{References}

[1] De Aquino, F. (2016).The Gravelectric Generator: Conversion of Gravitational Energy Directly Into

Electrical Energy, Bulletin of Pure \& Applied

Sciences- Physics Year : 2016, Volume : 35d,

Issue : 1and2 First page : (55) last page : ( 64$)$

Print ISSN : 0970-6569. Online ISSN : 2320-

3218. DOI : $10.5958 / 2320-3218.2016 .00008 .7$

[2] De Aquino, F. (2010) Mathematical Foundations of the Relativistic Theory of Quantum Gravity, Pacific Journal of Science and Technology, 11 (1), pp. 173-232.

Available at: https://hal.archives-ouvertes.fr/hal01128520

[3] De Aquino, F. (2012). Superconducting State generated by Cooper Pairs bound by Intensified Gravitational Interaction.

Available at http://vixra.org/abs/1207.0008 , v2.

[4] Valkengurg, V., (1992) Basic Electricity, Prompt Publications, 1-38.

[5] Fischer-Cripps, A., (2004). The electronics companion. CRC Press, p. 13, ISBN 9780750310123.

[6] Quevedo, C. P. (1977) Eletromagnetismo, McGraw-Hill, p. 107-108.

[7] U.S. Energy Information Administration (2013) http://www.eia.gov/tools/faqs/faq.cfm?id=97\&t=3 